\title{
The Independent Effect of Age Groups on the Effectiveness of Lifestyle Intervention
}

\author{
Danielle R. Bouchard • Jean-Patrice Baillargeon • \\ Marie-France Langlois
}

Published online: 5 January 2013

(C) Springer Science+Business Media New York 2013

\begin{abstract}
The impact of age on anthropometric measures, body composition, and metabolic risk factors following a lifestyle intervention is usually evaluated after adjustment for age at baseline; however, this strategy does not provide a clear clinical message other than age is a predictor of the responses. The objective of this review was to evaluate the independent effect of age groups on anthropometric measures, body composition, and metabolic risk factors following a lifestyle modification (exercise, diet, or combined intervention) in studies that included at least two different adult age groups. Eighty-five percent of studies reviewed reported significant differences among evaluated age groups on at least one studied outcome. In general, when a difference was observed among age groups, the advantage was to the oldest group studied, especially in the reduction of body weight, blood pressure, and type 2 diabetes risk. This is of crucial importance to health care providers because the
\end{abstract}

\section{R. Bouchard}

Faculty of Kinesiology and Recreation Management,

University of Manitoba, 318 Max Bell Centre,

Winnipeg, Manitoba R3T 2N2, Canada

\section{R. Bouchard $(\square)$}

Health, Leisure and Human Performance Research Institute,

University of Manitoba, 318 max Bell Centre,

Winnipeg, Manitoba R3T 2N2, Canada

e-mail: danielle_bouchard@umanitoba.ca

J.-P. Baillargeon • M.-F. Langlois

CRC Étienne LeBel du Centre hospitalier, Universitaire de Sherbrooke (C.H.U.S.), C.H.U.S. 3001, 12th North Avenue, Sherbrooke, Quebec, Canada J1H 5N4

\section{J.-P. Baillargeon • M.-F. Langlois}

Departement of Medicine, Division of Endocrinology, Faculté de médecine et des sciences de la santé, Université de Sherbrooke, C.H.U.S. 3001, 12th North Avenue,

Sherbrooke, Quebec, Canada J1H 5N4 impact of lifestyle modification interventions may be different among age groups. It is thus essential in future studies to stratify results by age group in order to provide a clear message on the impact of the intervention in different age groups, instead of merely adjusting results according to age.

Keywords Aging $\cdot$ Physical activity $\cdot$ Diet $\cdot$ Obesity Lifestyle

\section{Introduction}

Lifestyle is defined as a style of living that reflects the attitudes and values of a person or group of people. Lifestyle comprises several sub-categories including physical activity, diet, sleeping, alcohol consumption, and smoking [1]. This review article focuses on the effect of age groups on outcomes related to the modification of diet and physical activity.

Most industrialized countries report an important percentage of overweight or obese people among their populations and the World Health Organization has declared obesity as an epidemic [2]. Obesity significantly increases the risk of developing various serious health problems including type 2 diabetes, coronary heart disease [3], osteoarthritis [4], hypertension [5], Alzheimer's disease [6], sleep apnea [7], and dyslipidemia [8]. All these chronic conditions have in turn an impact on an individual's quality of life regardless of their age. Furthermore, health expenses related to obesity are increasing. For example, health costs increased by $40 \%$ in Canada between 1997 and 2004 [9] and it has been reported that an obese individual will cost the health system $\$ 1486$ more annually than a lean counterpart [10]. Lifestyle modification is one of the strategies to address the obesity epidemic and other chronic conditions 
[11]. However, it is still unclear whether lifestyle modification is sustainable and effective in all age groups.

Despite the fact that age is usually considered as a potential confounder and taken into consideration by the use of regression analysis, most do not report the results stratified by age group [12-16]. Nonetheless, modifications in diet and physical activity levels have shown positive impact in young [17], middle-aged [18], and older adults [19-22]. These findings demonstrate the importance of age on the response to a lifestyle intervention, but without direct comparison they cannot provide clinically useful information on the differences that should be expected among young, middle-aged, or older adults following the same lifestyle intervention. The optimal strategy to improve anthropometric measures, body composition, and metabolic risk factors following a lifestyle intervention could vary according to age groups for several reasons. Those reasons include body composition modification observed with aging [23, 24], obesity duration that can potentially be longer in older adults $[25,26]$ and different personal goals during the intervention [27].

Weight loss benefits in older adults have been challenged in the last decade especially because of the risk of losing fat-free mass and increasing mortality rate [28-32]. However, several studies have argued the contrary by showing weight-loss benefits in different age groups including older adults [33-35]. For example, one study including individuals over 35 years of age reported that an attempt at weight loss was in fact associated with lower allcause mortality, and that a higher mortality rate occurred only in those reporting unintentional weight loss [34]. A joint position statement has supported that weight-loss therapy improves physical function, quality of life, and reduces medical complications associated with obesity in older adults, and that bone and muscle mass can be preserved [35]. Furthermore, ideal weight and weight discrepancies are weakly associated with age and extra body weight is a concern in every age group [36]. The real question may not be whether or not we should promote weight loss in older adults, but whether we should promote weight loss in all age groups using the same approach?

\section{Methods}

There are at least two ways to explore the impact of age group on outcomes of lifestyle modification. First, it is possible to compare two studies that used a similar intervention with two different age samples (e.g., a lifestyle intervention study with adults aged 65 and older vs. a similar lifestyle intervention study with adults aged 1845 years) and make assumptions on the independent impact of age. Second, it is possible to perform studies formally exploring whether different age groups respond differently to the same intervention. This review article highlights available studies that formally tested the benefits of lifestyle intervention including diet, physical activity or a combination of both strategies in different age groups. The studied outcomes were regrouped into three categories: anthropometric characteristics, body composition, and metabolic risk factor improvement.

To identify the independent role of a specific age group in response to the same lifestyle intervention, electronic searches of MEDLINE (until February 2011) were performed using individual or a combination of different terms. Search keywords were: lifestyle and age, exercise and age, diet and age, intervention and age, weight loss and age, age group, age effect, aging, and obesity and age. Only English language articles were screened. The inclusion criteria were: 1 - formally tested the benefits of the same lifestyle intervention in adults ( $\geq 18$ years old) including diet, physical activity or both in two or more age groups; - 2- reported change in anthropometric characteristics, body composition, or metabolic risk factors. A total of 312 articles were identified by reading abstracts as potential articles to be included in this review. The articles were then screened by one of the authors (DRB) to identify articles reporting results by two or more age groups. Most articles were rejected because results were not stratified by age in secondary analyses. The remaining articles were rejected because the studied outcomes did not include anthropometric measures, body composition, or metabolic profile.

As a result, a total of 13 studies were identified. Table 1 gives a summary of the outcomes reported in those studies and specifies whether the oldest age group for each outcome had greater, lower, or equal benefits compared to younger age groups. Some articles reported one of more outcomes while others only reported one outcome. Table 2 reports the selected studies in detail.

\section{Anthropometric Measures}

\section{Body Weight}

At any age, one of the main objectives of lifestyle modification is to reduce body weight to treat or prevent obesity related co-morbidities. The magnitude of change in body weight observed after a lifestyle intervention depends mostly on the duration and the intensity of the intervention. As presented in Table 1, body weight change following a lifestyle intervention was the outcome most frequently evaluated among identified studies. Seven studies have formally investigated the effect of age group on body weight reduction following the same lifestyle intervention [37-43]. In general, these studies suggest that lifestyle intervention is 
Table 1 Summary of studies that formally compared age group following a lifestyle intervention
$\Uparrow$ Greater benefits as compared to younger age group

$\Downarrow$ Lower benefits as compared to younger age group

$\Leftrightarrow$ Equal benefits as compared to younger age group

\begin{tabular}{|c|c|c|c|c|c|c|c|}
\hline Outcome & Older & oup $v_{s}$ & nger age & & & & \\
\hline \multicolumn{8}{|c|}{ Anthropometric characteristics } \\
\hline Body weight & $\Leftrightarrow^{37}$ & $\Uparrow^{38}$ & $\Leftrightarrow^{39}$ & $\Downarrow^{40}$ & $\Leftrightarrow \Leftrightarrow^{41}$ & $\Uparrow^{42}$ & $\Uparrow^{43}$ \\
\hline Waist circumference & $\Leftrightarrow^{37}$ & $\Uparrow^{38}$ & $\Leftrightarrow^{39}$ & $\Leftrightarrow^{47}$ & & & \\
\hline BMI & $\Leftrightarrow^{37}$ & $\Leftrightarrow^{39}$ & $\Leftrightarrow^{47}$ & & & & \\
\hline \multicolumn{7}{|l|}{ Body composition } & \\
\hline Fat mass & $\Leftrightarrow 39$ & $\Downarrow^{40}$ & & & & & \\
\hline Fat-free mass & $\Downarrow^{39}$ & & & & & & \\
\hline Bone density & $\Leftrightarrow^{53}$ & & & & & & \\
\hline \multicolumn{7}{|l|}{ Metabolic profile } & \\
\hline Glycemia & $\Uparrow^{38}$ & $\Uparrow^{39}$ & $\Uparrow^{63}$ & & & & \\
\hline Blood pressure & $\Uparrow^{39}$ & $\Uparrow^{41}$ & $\Uparrow \Leftrightarrow^{47}$ & $\Uparrow^{70}$ & $\Leftrightarrow{ }^{72}$ & & \\
\hline Blood lipids & $\Leftrightarrow \Uparrow^{39}$ & $\Downarrow^{47}$ & $\Leftrightarrow^{76}$ & & & & \\
\hline
\end{tabular}

associated with a significant decrease in body weight for all age groups. However, four out of seven studies [39, 41-43] reported a significant difference among age groups, while the others did not $[37,38,40]$. Interestingly, three of the four studies reporting a difference among age groups showed the greatest benefit in the oldest group compared with the younger age groups. The greater body weight loss observed in the oldest group could be influenced by the fact that older adults are less likely to be employed, have fewer social responsibilities, and therefore have more time to devote to the intervention and follow advices given by the research group [38]. Moreover, older adults may be more aware of disease vulnerability having previously lost a loved one or having already suffered from a worrisome event. More recently, a 10-year follow-up from the Diabetes Prevention Program (DPP) showed that differences among age groups observed after the three years intervention [38] persisted in long term follow-up [44••]. The authors also reported in their long term follow-up study that body weight loss was less sustained in participants younger than 45 years than those aged 45 years and older at baseline [44••]. This latest result suggests that age groups may respond differently not only to initial bodyweight reduction, but also to long-term weight loss maintenance. Altogether, these results confirm that older adults are able to modify their lifestyle habits in order to lose weight despite a general assumption that they have an encrypted lifestyle $[45,46]$.

\section{Waist Circumference and Body Mass Index}

Three out of the four studies that have investigated age group waist circumference (WC) and body mass index (BMI) response to a lifestyle intervention [37, 39, 47], have reported a significant reduction in WC and BMI following an intervention, but did not report any significant difference among age groups. In contrast to this finding, in one study
[38] with a threefold longer follow up, the authors reported a greater decrease in $\mathrm{WC}$ in the oldest group $(P \leq 0.05)$, but did not report information with regard to BMI. Notably, this study included a higher physical activity volume during the initial intervention compared to the other three interventions. In fact, the objective of the DPP study [38] was to reach a minimum of $150 \mathrm{~min} /$ week while two of the abovementioned studies [37,39] recommended exercising twice a week without specifying duration. However, it is likely that those two interventions did not include 75 minutes per session. This result suggests that compared with younger adults, older participants may respond better to a lifestyle intervention recommending higher durations of physical activity to achieve a significant reduction of WC. This is in line with studies that reported a decrease in WC during interventions comprising a similar volume of physical activity ( $\sim 150$ minutes per week) with or without weight loss $[13,48]$.

In summary, four out of the seven studies that formally tested the influence of age group on anthropometric measures in response to lifestyle interventions found differences among age groups with the greatest benefits in the oldest group. Thus, modifications in lifestyle might induce greater anthropometric improvement in older adults compared to younger adults.

\section{Body Composition Following a Lifestyle Intervention}

In older adults who experience inevitable loss of muscle mass and bone mass [49], another important aim of lifestyle intervention is to preserve fat-free mass and bone mass while significantly reducing fat mass. However, reductions in fat-free mass (FFM) [50] and bone mass [51] are almost inevitable with any weight loss program, especially if weight loss is achieved using caloric restriction as the sole 


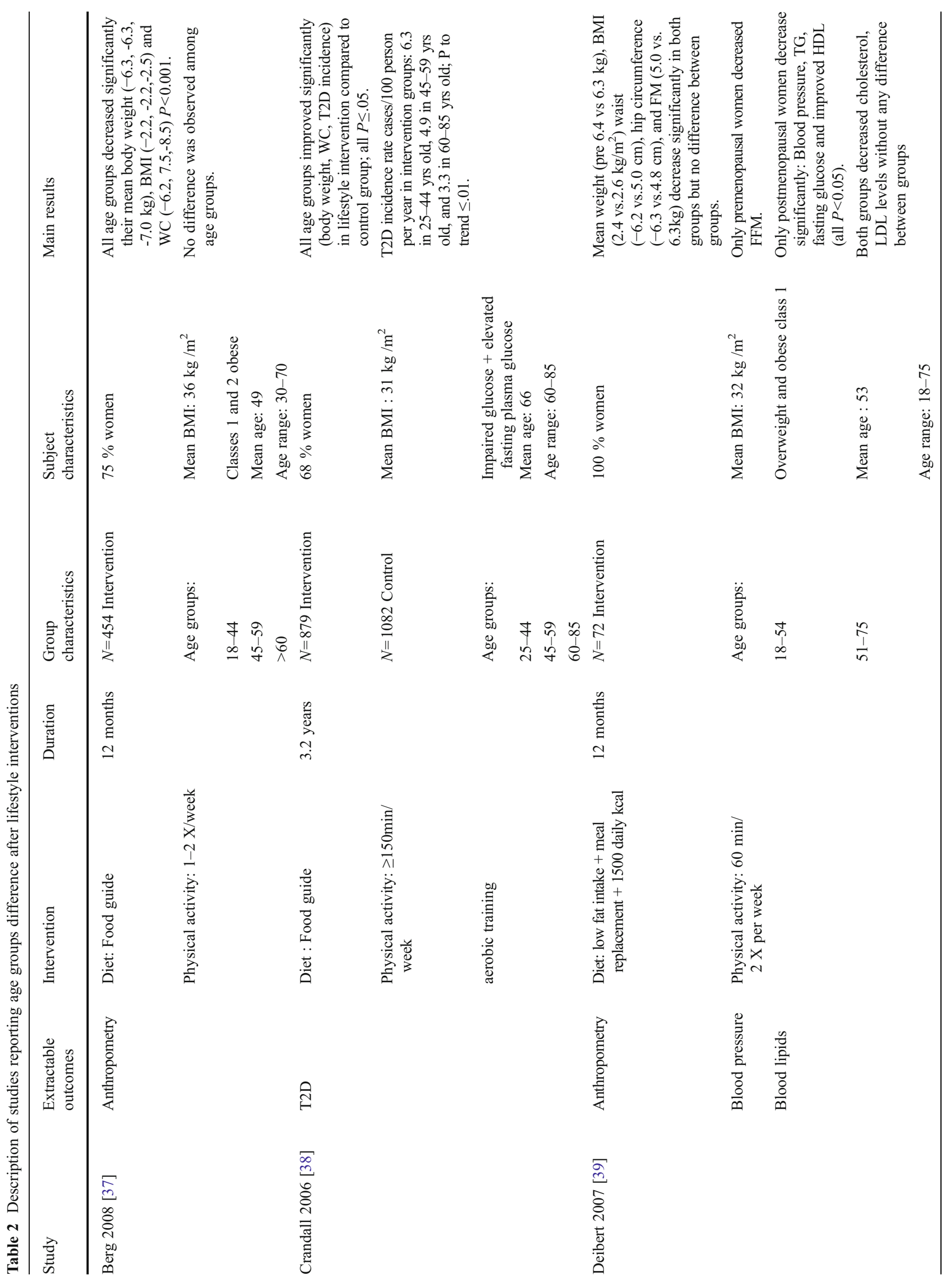




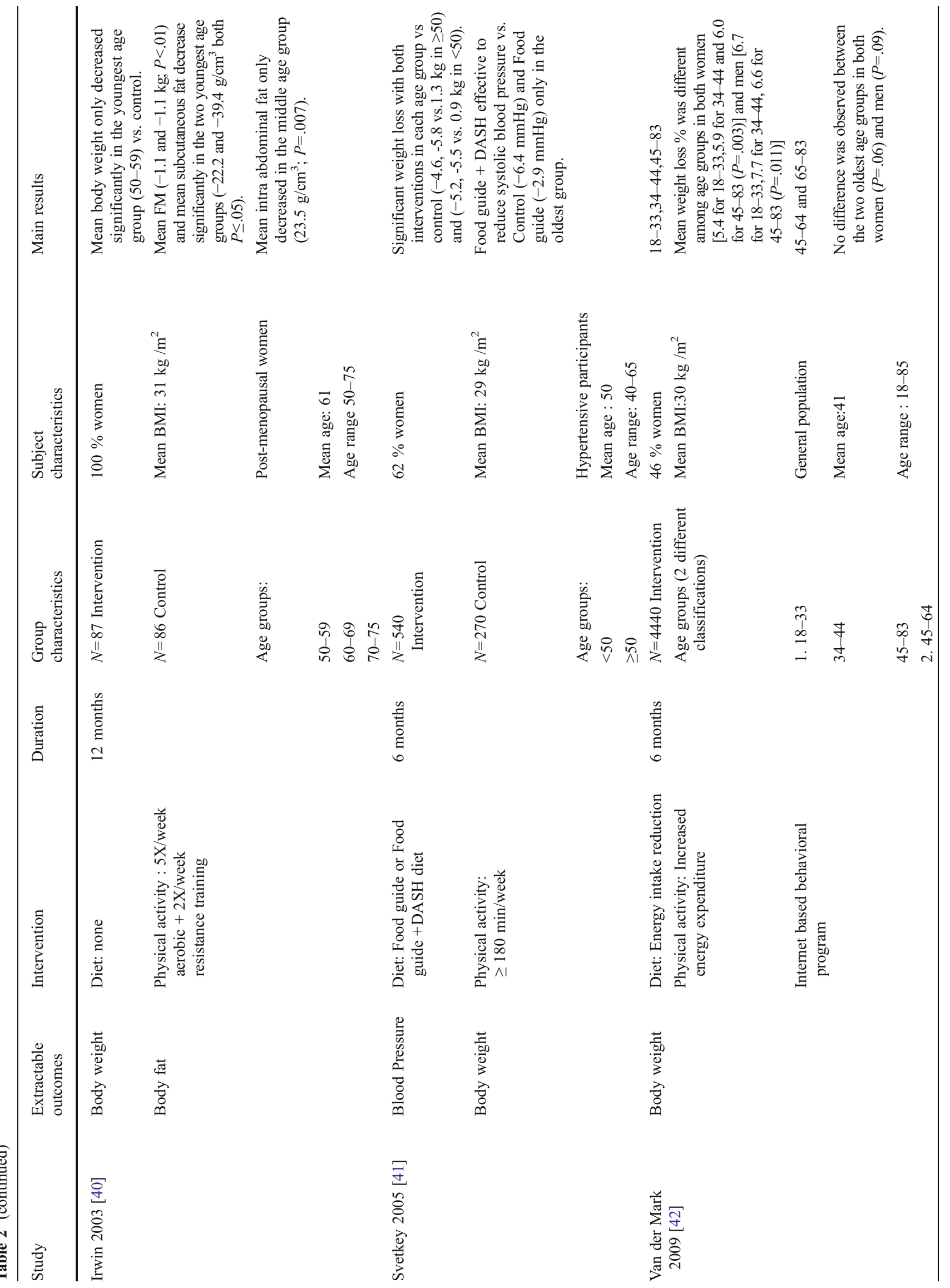




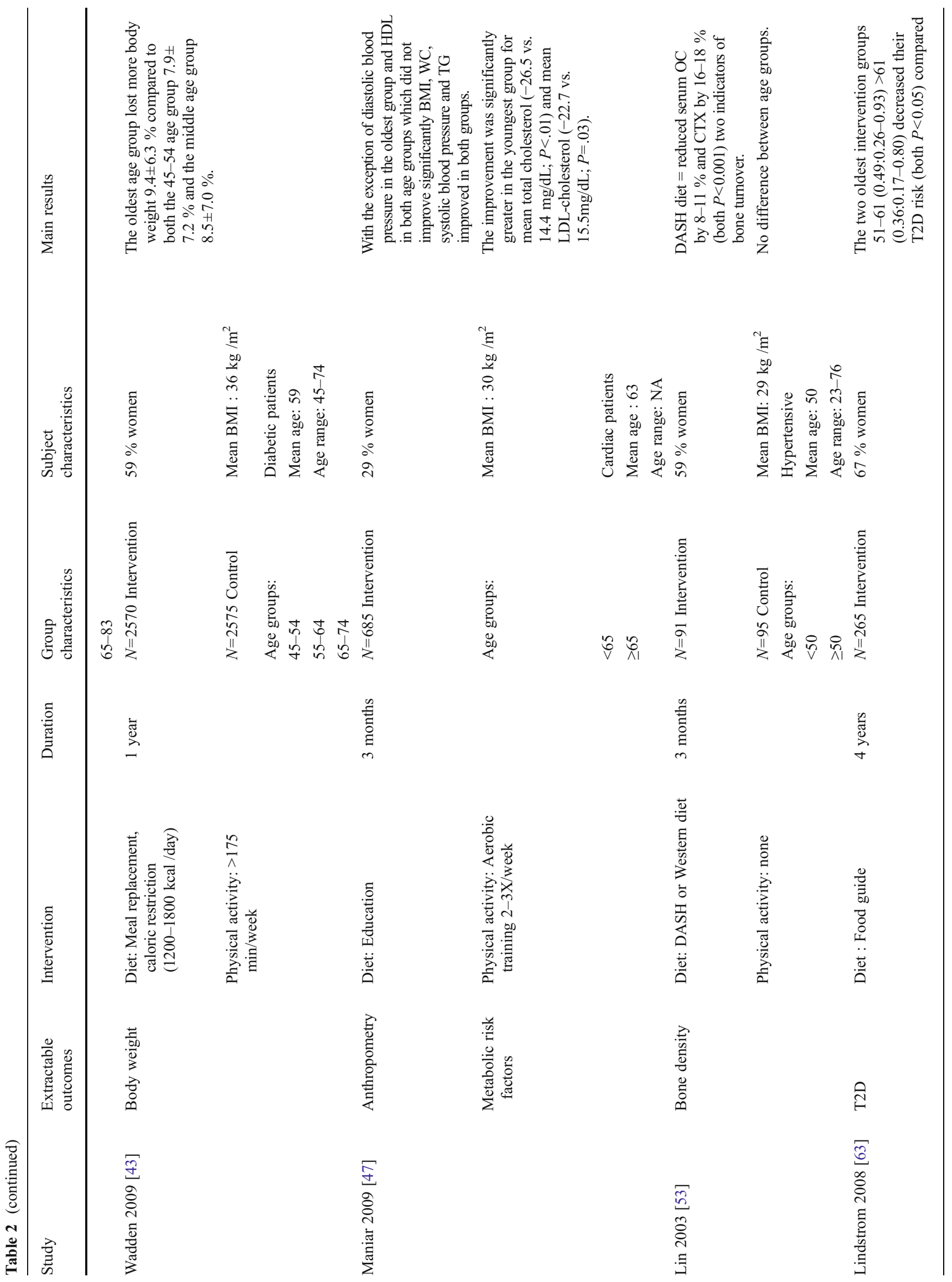




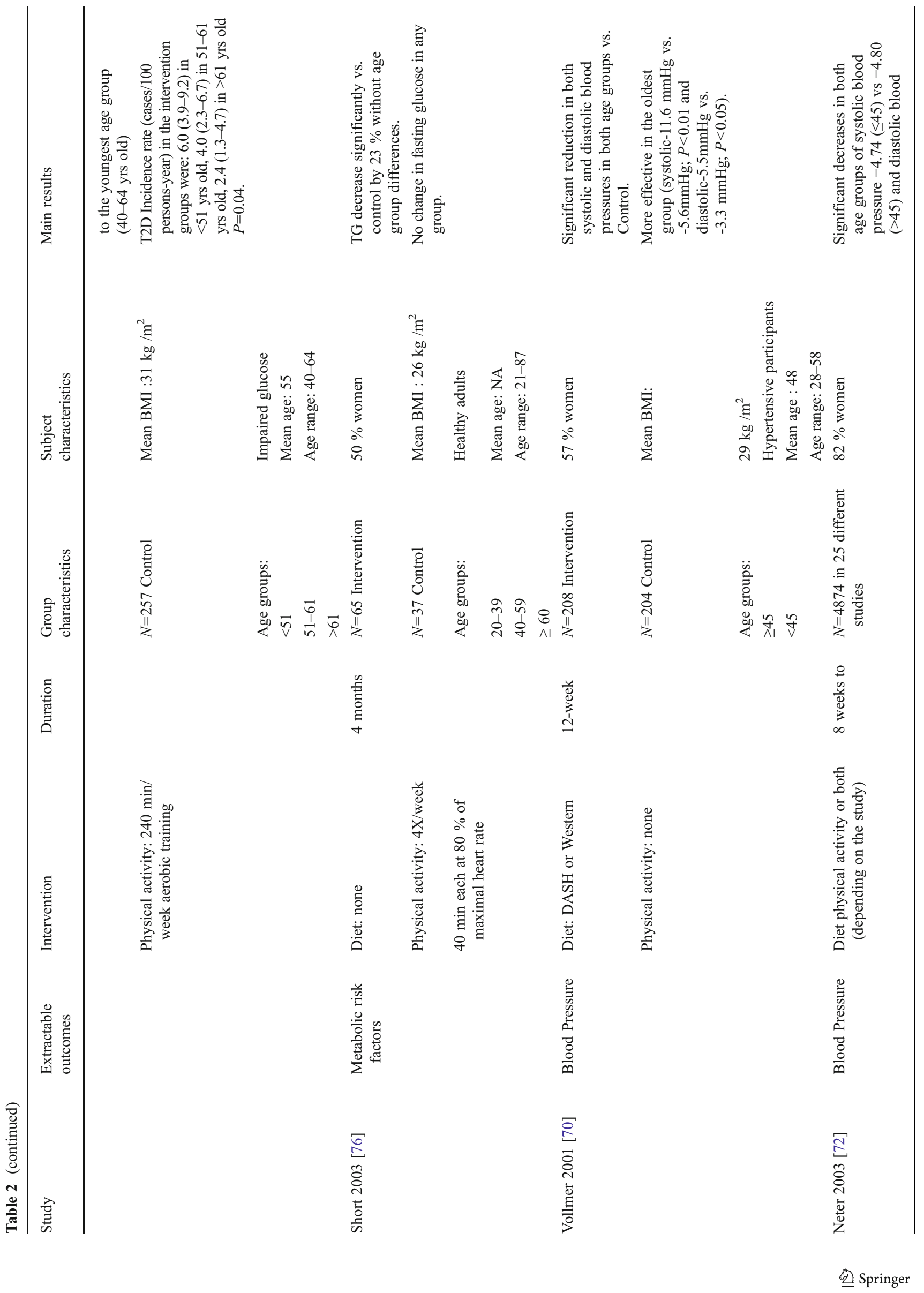


strategy. By combining resistance training with caloric restriction, some authors have demonstrated the possibility of maintaining FFM even in older adults [19, 52]. However, another study by Brochu et al. [20] reported a significant decrease in FFM despite the fact that caloric restriction was combined with a resistance training program in postmenopausal women. Surprisingly, only a few studies have specifically reported the independent influence of age on changes in body composition following a lifestyle intervention [39, 40, 53].

\section{Fat Mass}

Only two studies were identified in which the authors formally tested the changes in fat mass (FM) after a lifestyle intervention in different age groups [39, 40]. First, one study has reported significant FM decreases in both age groups of pre- and post-menopausal women (both $P<$ 0.01 ), but no difference was observed in the magnitude of change between groups [39]. In contrast, another study has demonstrated that FM was significantly decreased in groups aged between 50-59 and 60-69 years, but not in the oldest group aged between 70 and 75 years following a 12-month physical activity intervention [40]. The difference between the two studies might be explained by the fact that subjects in the oldest age group in the last study were aged 73 yrs old in average [40] while the mean age in the oldest age group for the first study was 58 yrs old [39]. Moreover, the first study combined both physical activity and diet [39] while the second [40] relied solely on physical activity to decrease FM. This result implies that it is possible to reduce FM in all age groups but FM reduction might not be observed in the elderly ( $\geq 70$ years old) especially when only exercise is part of the intervention. More studies using the same stratification of age and including men are needed to confirm this observation.

Similar to total FM, abdominal and visceral fat distributions have been identified as conferring important health risks [54, 55]. However, to our knowledge, only one study examined changes in intra-abdominal and subcutaneous fat deposits after a lifestyle intervention in two or more age groups [40]. This study reported that only the middle age group (60-69 yrs old) showed a decrease in both intra-abdominal $\left(-23.5 \mathrm{~g} / \mathrm{cm}^{2} ; P=0.007\right)$ and subcutaneous FM $\left(-39.4 \mathrm{~g} / \mathrm{cm}^{2} ; P \leq 0.05\right)$ after a 12month physical activity intervention. The youngest age group (50-59 yrs old) only decreased subcutaneous fat content $\left(-22.2 \mathrm{~g} / \mathrm{cm}^{2} ; P=0.03\right)$ while no such decrease was observed in the oldest group (70-75 yrs old). As observed in most studies that report age group comparisons, the oldest age group had a small sample which can affect the statistical power to detect any change in this subgroup. 


\section{Fat-Free Mass}

One of the reasons why controversy exists in promoting weight loss in older adults is the risk of fat-free mass (FFM) loss [35, 56]. To our knowledge, only one study has formally tested FFM modification in two or more age groups after the same lifestyle intervention [39]. However, Hunter et al. [52] reported that it is possible to maintain FFM if a caloric restriction induced by diet is associated to resistance exercise training in middle age women while Brochu et al. [20], reported the inverse in older women. Those two studies support that the effect of a similar intervention might induce different results based on age group. The study that formally tested FFM modification in two or more age groups after a lifestyle intervention reported that FFM decreased to a lower extent in postmenopausal women compared with premenopausal women ( $-3 \%$ of total weight loss vs. $-21 \%, P<0.01)$ after a 12 -month intervention including both physical activity and diet. This result is quite interesting since total weight reduction was similar between groups. Therefore, based on this unique study, it might be proposed that preservation of FFM is feasible in postmenopausal women that combine caloric restriction and physical activity in order to improve obesity-related conditions.

\section{Bone Mass}

Another important concern of lifestyle interventions inducing weight loss, especially in older adults, is the loss of bone mass [35]. Reduction in bone mass is almost inevitable with any weight loss program [51], especially if weight loss is achieved solely by caloric intake restriction [51]. However, progressive weight loss associated with exercise also reduces bone-mass loss [33], although it is still not clear which type of exercise is preferable to preserve bone-mass. Weight bearing activities and resistance training are usually beneficial in the prevention and treatment of osteoporosis [57]; but during a weight loss program, studies have demonstrated that the tendency to reduce bone mass remains even when caloric restriction is combined with resistance training and weight bearing exercise [58, 59]. Nonetheless, even if an unfavorable, accelerated bone turnover is observed during weight loss, the potential negative consequences do not outweigh the numerous other health benefits of weight loss [60]. Only one study was identified in which the independent effect of age was reported after a lifestyle intervention [53]. This study included 186 participants and was conducted in a broad age sample (23-76 yrs old). The primary objective of the intervention was to decrease salt consumption by adopting the dietary approaches to stop hypertension (DASH) diet, although it also aimed at adopting a healthy overall diet [53]. The DASH diet was originally developed as an eating style to help lower blood pressure, but it has been found to have many additional advantages. The DASH diet is rich in fruits, vegetables, whole grains, and low-fat dairy foods, and is limited in sugar-sweetened foods and beverages, red meat, and added fats. In a study by Lin et al. [53], participants were divided into two age groups $(<50 v s . \geq 50 \mathrm{yrs})$ and data was collected following a 12-week intervention. The authors demonstrated that the DASH diet, without any exercise intervention, significantly reduced serum osteocalcin and carboxy-terminal collagen crosslinks, two indicators confirming that the DASH diet increases bone mineral status. However, no significant difference in bone mass was observed between age groups. The absence of differential effect of age on bone mineral density after a lifestyle intervention reported in humans was also observed in animal models following a 12 -week physical activity intervention [61].

\section{Metabolic Outcomes}

At any age, obesity increases the risk of developing a wide range of co-morbidities including type 2 diabetes and cardiovascular diseases [62]. Besides improving anthropometric characteristics and body composition, lifestyle interventions also focus on preventing and treating these conditions.

\section{Glycemia and Type 2 Diabetes (T2D)}

Although a large number of published studies are available in the current scientific literature regarding the impact of lifestyle modification on the control of glycemia, only three studies were identified in which the authors formally tested the independent effect among age groups [38, 39, 63]. The three studies combined physical activity with caloric restriction in a total of more than 2500 participants. All studies reported a beneficial impact of the intervention in the oldest age groups [38, 39, 63]. However, only two out of the three studies reported a beneficial impact in the youngest age groups studied [38, 39].

Besides a beneficial impact of the intervention in the oldest age group, one study reported that the oldest group presented with a significantly lower incidence rate of T2D compared to both younger age groups studied: 6.3 (2544 yrs old), 4.9 (45-59 yrs old) and 3.3 (60-85 yrs old) cases per 100 person-years $(P<0.01)$ [38, 39]. After a 10year follow-up of this study, the lowest T2D incidence in the oldest age group remained significant [44••]. Similar findings were reported in a Finnish study [63], in which the oldest group presented the lowest incidence rate after a median follow-up of four years: 2.4 (>61 yrs), 4.0 (51$61 \mathrm{yrs})$ and 6.0 ( $<51 \mathrm{yrs})$ cases per 100 person-years 
$\left(\mathrm{P}_{\text {trend }}=0.0039\right)$. Based on the strong study's methodology, it may be concluded that individuals over 60 years of age pull greater benefits from a lifestyle intervention combining physical activity and caloric restriction compared to younger adults to prevent $\mathrm{T} 2 \mathrm{D}$.

\section{Blood Pressure}

High blood pressure is a highly prevalent chronic condition in our modern society [64], and the fact that more than half of the population is either overweight or obese is contributing to this high prevalence [65]. A major strategy to treat hypertension is diet modification (weight loss and/or reduced salt intake) and physical activity [39, 41, 47, 66-71]. We have found four studies [39, 41, 47, 70] and a meta-analysis [72] that formally tested the influence of two or more age groups on blood pressure response following a lifestyle intervention. Svetkey et al.[41] has demonstrated that both age groups of hypertensive participants $(<50$ and $\geq 50$ yrs old $)$ significantly decreased their blood pressure compared to the control group $(P<0.01)$, without difference among age groups. However, when the intervention included the established recommendations plus DASH diet, the oldest age group decreased their systolic blood pressure significantly compared with the youngest age group. This response might be the result of a higher baseline value in older adults as it is well established that blood pressure increases with age [73] and that this higher initial value is associated with greater overall improvement [74]. Similar findings were reported with a shorter intervention [70] by dividing the results into two age groups ( $\geq 45$ yrs and $<45$ yrs). The authors of this study reported that all subgroup participants lowered their blood pressure but the DASH diet produced the greatest effect in the older age group in decreasing systolic (-11.6vs.-5.6) and diastolic (-5.5 vs.3.3) blood pressure, compared to the younger age group (both $P<.05)$. Finally, Deibert et al. [39] also reported a greater blood pressure decrease in the older age group after a 24week lifestyle intervention including diet and physical activity [39]. In contrast to findings by the three studies above, one study [47] did not report any differences among age groups in terms of systolic blood pressure and a greater decrease for diastolic blood pressure in the younger age group. The inverse result observed in the later study was confirmed in a metaanalysis summarizing the impact of weight-loss interventions on blood pressure in a total of 4874 participants [72]. Note that no study integrated in this meta-analysis was included in our review. In fact, the meta-analysis did not report age group differences in each study, but only compiled results of all studies and compared the general result for all studies included in the meta-analysis for two age groups $(\geq 45 \mathrm{yrs}$ and $<45 \mathrm{yrs}$ ). The meta-analysis concluded that both age groups showed a decrease in blood pressure values following a lifestyle intervention without any difference between age groups. The conclusion of this meta-analysis is thus discordant to the findings of three of the four clinical trials reported above, which concluded that age may affect the impact of lifestyle intervention on blood pressure with an advantage to the older age group. This might be explained in part by the fact that the studies included in the meta-analysis were not all hypertensive while all participants included in the clinical trials were. So, based on the most robust evidence available, hypertensive older age groups respond more positively than younger ones to a lifestyle intervention to decrease blood pressure.

\section{Lipid Profile}

Most weight loss studies including lifestyle modification also aim to improve lipid profiles, including triglycerides (TG) and cholesterol (total, LDL-chol and HDL-chol). According to a recent systematic review, weight loss produces a modest change in lipid profile in adults aged between 18 and 65 years, with a greater difference observed if weight loss is maintained over a period of two years or more [75]. Nonetheless, many studies have shown that age is associated with altered lipid profile, and that higher initial values are associated with a greater positive effect following lifestyle modification [74]. However, studies that have verified the independent impact of lifestyle modification on lipid profile by age group are scarce. Only three studies were identified in which the influence of age on lipid profile changes was formally tested and all three reported different findings depending on the specific outcome and the studied population. First, Deibert et al. [39] showed that a 12-month intervention combining physical activity and diet induced a significant reduction in total cholesterol and LDL-chol in both the older and the younger age groups. However, no difference was observed between the different age groups. HDL-chol levels increased significantly and TG levels decreased significantly only in the oldest age group. Second, with the use of aerobic exercise as the sole intervention, one study reported no TG difference between age groups (20 $39,40-59$ and $>60$ yrs old) [76]. Third, a study in a cardiac rehabilitation program including diet education and aerobic physical activity reported no improvement in both age groups for HDL-chol while similar improvement was reported between age groups for TG [47]. Finally, only the youngest group significantly decreased total and LDL-chol after the intervention. These studies show that lipid profile response may differ among age groups according to the intervention, the population, and the lipid marker studied.

\section{Limitations}

In all reviewed studies, most were not specifically designed to verify the impact of age or the outcomes of interest for 
this review were not studied. Consequently, the identification of selected articles was usually impossible by only keyword searches of the titles or abstracts but searching in articles themselves increased the number of studies that could be included in this review. Thus, some studies having reported secondary results by age group might not be included in this review. Another limitation is that some age groups were relatively small and may be statistically underpowered to report differential impacts of lifestyle modification. Moreover, interventions of the studies assessed in this review included various combinations of physical activity, diet quality or caloric restriction intervention that may explain different responses among age groups.

\section{Conclusion}

Even though age is known to be an important factor associated with many outcomes following a lifestyle intervention, this review demonstrates that few studies have formally tested the independent effect of age groups on the beneficial effects of lifestyle interventions. In general, our results show that the oldest age groups experience equal or greater benefits, at least in regard to body weight, blood pressure, and type 2 diabetes prevention. This result is of crucial importance to health care providers because they can expect different responses to lifestyle modification interventions based on the initial age groups of their clients. Furthermore, our results suggest that health benefits might outweigh risks of modifying lifestyles in older age groups.

Acknowledgment The authors thank Rachel Connelly for editing help.

Disclosure No potential conflicts of interest relevant to this article were reported.

\section{References}

Papers of particular interest, published recently, have been highlighted as:

•• Of major importance

1. Blaxter M. Health and lifestyle. New York: Taylor \& Francis; 2004.

2. WHO. Global Database on Body Mass Index: an interactive surveillance tool for monitoring nutrition transition $2011 \mathrm{http}$ ://apps.who.int/bmi/index.jsp. Accessed March 152012.

3. Alexander JK. Obesity and coronary heart disease. Am J Med Sci. 2001;321(4):215-24.

4. Messier SP. Osteoarthritis of the knee and associated factors of age and obesity: effects on gait. Med Sci Sports Exerc. 1994;26 (12):1446-52.
5. Barrett-Connor E. Obesity, hypertension and stroke. Clin Exp Hypertens A. 1990;12(5):769-82.

6. Gustafson D, Rothenberg E, Blennow K, Steen B, Skoog I. An 18year follow-up of overweight and risk of Alzheimer disease. Arch Intern Med. 2003;163(13):1524-8.

7. Khaodhiar L, McCowen KC, Blackburn GL. Obesity and its comorbid conditions. Clin Cornerstone. 1999;2(3):17-31.

8. Miller WM, Nori-Janosz KE, Lillystone M, Yanez J, McCullough PA. Obesity and lipids. Curr Cardiol Rep. 2005;7(6):465-70.

9. Birmingham CL, Muller JL, Palepu A, Spinelli JJ, Anis AH. The cost of obesity in Canada. CMAJ. 1999;160(4):483-8.

10. Finkelstein EA, Fiebelkorn IC, Wang G. National medical spending attributable to overweight and obesity: how much, and who's paying? Health Aff (Millwood). 2003;W3:219-26.

11. Heath V. Obesity: benefits of intensive lifestyle modification programs in the spotlight. Nat Rev Endocrinol. 2011;7(1):1.

12. Bouchard DR, Beliaeff S, Dionne IJ, Brochu M. Fat mass but not fat-free mass is related to physical capacity in well-functioning older individuals: nutrition as a determinant of successful aging (NuAge)-the Quebec Longitudinal Study. J Gerontol A Biol Sci Med Sci. 2007;62(12):1382-8.

13. Davidson LE, Hudson R, Kilpatrick K, Kuk JL, McMillan K, Janiszewski PM, Lee S, Lam M, Ross R. Effects of exercise modality on insulin resistance and functional limitation in older adults: a randomized controlled trial. Arch Intern Med. 2009;169 (2):122-31.

14. Janssen I, Heymsfield SB, Ross R. Low relative skeletal muscle mass (sarcopenia) in older persons is associated with functional impairment and physical disability. J Am Geriatr Soc. 2002;50 (5):889-96

15. Sternfeld B, Ngo L, Satariano WA, Tager IB. Associations of body composition with physical performance and self-reported functional limitation in elderly men and women. Am J Epidemiol. 2002;156(2):110-21.

16. Visser M, Langlois J, Guralnik JM, Cauley JA, Kronmal RA, Robbins J, Williamson JD, Harris TB. High body fatness, but not low fat-free mass, predicts disability in older men and women: the Cardiovascular Health Study. Am J Clin Nutr. 1998;68(3):584-90.

17. Diaz RG, Esparza-Romero J, Moya-Camarena SY, Robles-Sardin AE, Valencia ME. Lifestyle intervention in primary care settings improves obesity parameters among Mexican youth. J Am Diet Assoc. 2010;110(2):285-90.

18. Li G, Zhang P, Wang J, Gregg EW, Yang W, Gong Q, Li H, Jiang Y, An Y, Shuai Y, Zhang B, Zhang J, Thompson TJ, Gerzoff RB, Roglic $\mathrm{G}, \mathrm{Hu} \mathrm{Y}$, Bennett PH. The long-term effect of lifestyle interventions to prevent diabetes in the China Da Qing Diabetes Prevention Study: a 20-year follow-up study. Lancet. 2008;371(9626):1783-9.

19. Bouchard DR, Soucy L, Senechal M, Dionne IJ, Brochu M. Impact of resistance training with or without caloric restriction on physical capacity in obese older women. Menopause. 2008;16(1):66-72.

20. Brochu M, Malita MF, Messier V, Doucet E, Strychar I, Lavoie JM, Prud'homme D, Rabasa-Lhoret R. Resistance training does not contribute to improving the metabolic profile after a 6-month weight loss program in overweight and obese postmenopausal women. J Clin Endocrinol Metab. 2009;94(9):3226-33.

21. Messier SP, Loeser RF, Miller GD, Morgan TM, Rejeski WJ, Sevick MA, Ettinger Jr WH, Pahor M, Williamson JD. Exercise and dietary weight loss in overweight and obese older adults with knee osteoarthritis: the arthritis, diet, and activity promotion trial. Arthritis Rheum. 2004;50(5):1501-10.

22. Villareal DT, Banks M, Siener C, Sinacore DR, Klein S. Physical frailty and body composition in obese elderly men and women. Obes Res. 2004;12(6):913-20.

23. Ardern CI, Janssen I, Ross R, Katzmarzyk PT. Development of health-related waist circumference thresholds within BMI categories. Obes Res. 2004;12(7):1094-103. 
24. Gallagher D, Heymsfield SB, Heo M, Jebb SA, Murgatroyd PR, Sakamoto Y. Healthy percentage body fat ranges: an approach for developing guidelines based on body mass index. Am J Clin Nutr. 2000;72(3):694-701.

25. Janssen I, Bacon E. Effect of current and midlife obesity status on mortality risk in the elderly. Obesity (Silver Spring). 2008;16 (11):2504-9.

26. Stenholm S, Rantanen T, Alanen E, Reunanen A, Sainio P, Koskinen S. Obesity history as a predictor of walking limitation at old age. Obesity (Silver Spring). 2007;15(4):929-38.

27. Wamsteker EW, Geenen R, Zelissen PM, van Furth EF, Iestra J. Unrealistic weight-loss goals among obese patients are associated with age and causal attributions. J Am Diet Assoc. 2009;109 (11):1903-8.

28. Bradway C, DiResta J, Fleshner I, Polomano RC. Obesity in nursing homes: a critical review. J Am Geriatr Soc. 2008;56 (8):1528-35.

29. Janssen I, Katzmarzyk PT, Ross R. Body mass index is inversely related to mortality in older people after adjustment for waist circumference. J Am Geriatr Soc. 2005;53(12):2112-8.

30. Rejeski WJ, Marsh AP, Chmelo E, Rejeski JJ. Obesity, intentional weight loss and physical disability in older adults. Obes Rev. 2009;11(9):671-85.

31. Reynolds SL, McIlvane JM. The impact of obesity and arthritis on active life expectancy in older Americans. Obesity (Silver Spring). 2009;17(2):363-9.

32. Stenholm S, Koster A, Alley DE, Houston DK, Kanaya A, Lee JS, Newman AB, Satterfield S, Simonsick EM, Visser M, Harris TB, Ferrucci L. Joint association of obesity and metabolic syndrome with incident mobility limitation in older men and women-results from the Health, Aging, and Body Composition Study. J Gerontol A Biol Sci Med Sci. 2010;65(1):84-92.

33. Gallagher D, Kovera AJ, Clay-Williams G, Agin D, Leone P, Albu J, Matthews DE, Heymsfield SB. Weight loss in postmenopausal obesity: no adverse alterations in body composition and protein metabolism. Am J Physiol Endocrinol Metab. 2000;279(1):E12431

34. Gregg EW, Gerzoff RB, Thompson TJ, Williamson DF. Intentional weight loss and death in overweight and obese U.S. adults 35 years of age and older. Ann Intern Med. 2003;138(5):383-9.

35. Villareal DT, Apovian CM, Kushner RF, Klein S. Obesity in older adults: technical review and position statement of the American Society for Nutrition and NAASO, The Obesity Society. Obes Res. 2005;13(11):1849-63.

36. Pliner P, Chaiken S, Flett GL. Gender differences in concern with body weight and physical appearance over the life span. Pers Soc Psychol Bull. 2010;16(2):263-73.

37. Berg A, Frey I, Konig D, Predel HG. Exercise based lifestyle intervention in obese adults: results of the intervention study m.o.B.I.L.I.s. Dtsch Arztebl Int. 2008;105(11):197-203.

38. Crandall J, Schade D, Ma Y, Fujimoto WY, Barrett-Connor E, Fowler S, Dagogo-Jack S, Andres R. The influence of age on the effects of lifestyle modification and metformin in prevention of diabetes. J Gerontol A Biol Sci Med Sci. 2006;61(10):1075-81.

39. Deibert P, Konig D, Vitolins MZ, Landmann U, Frey I, Zahradnik HP, Berg A. Effect of a weight loss intervention on anthropometric measures and metabolic risk factors in pre- versus postmenopausal women. Nutr J. 2007;6:31.

40. Irwin ML, Yasui Y, Ulrich CM, Bowen D, Rudolph RE, Schwartz RS, Yukawa M, Aiello E, Potter JD, McTiernan A. Effect of exercise on total and intra-abdominal body fat in postmenopausal women: a randomized controlled trial. JAMA. 2003;289(3):323-30.

41. Svetkey LP, Erlinger TP, Vollmer WM, Feldstein A, Cooper LS, Appel LJ, Ard JD, Elmer PJ, Harsha D, Stevens VJ. Effect of lifestyle modifications on blood pressure by race, sex, hypertension status, and age. J Hum Hypertens. 2005;19(1):21-31.
42. van der Mark M, Jonasson J, Svensson M, Linne Y, Rossner S, Lagerros YT. Older members perform better in an internet-based behavioral weight loss program compared to younger members. Obes Facts. 2009;2(2):74-9.

43. Wadden TA, West DS, Neiberg RH, Wing RR, Ryan DH, Johnson KC, Foreyt JP, Hill JO, Trence DL, Vitolins MZ. One-year weight losses in the Look AHEAD study: factors associated with success. Obesity (Silver Spring). 2009;17(4):713-22.

44.• Knowler WC, Fowler SE, Hamman RF, Christophi CA, Hoffman HJ, Brenneman AT, Brown-Friday JO, Goldberg R, Venditti E, Nathan DM. 10-year follow-up of diabetes incidence and weight loss in the Diabetes Prevention Program Outcomes Study. Lancet. 2009;374(9702):1677-86. This study showed that the difference magnitude of changes between age groups after a lifestyle modification program was maintained even after 10 years.

45. Svendsen OL, Hassager C, Christiansen C. Age- and menopauseassociated variations in body composition and fat distribution in healthy women as measured by dual-energy X-ray absorptiometry. Metabolism. 1995;44(3):369-73.

46. Whelton PK, Appel LJ, Espeland MA, Applegate WB, Ettinger Jr WH, Kostis JB, Kumanyika S, Lacy CR, Johnson KC, Folmar S, Cutler JA. Sodium reduction and weight loss in the treatment of hypertension in older persons: a randomized controlled trial of nonpharmacologic interventions in the elderly (TONE). TONE Collaborative Research Group. JAMA. 1998;279(11):839-46.

47. Maniar S, Sanderson BK, Bittner V. Comparison of baseline characteristics and outcomes in younger and older patients completing cardiac rehabilitation. J Cardiopulm Rehabil Prev. 2009;29(4):220-9.

48. Ross R, Janssen I, Dawson J, Kungl AM, Kuk JL, Wong SL, Nguyen-Duy TB, Lee S, Kilpatrick K, Hudson R. Exerciseinduced reduction in obesity and insulin resistance in women: a randomized controlled trial. Obes Res. 2004;12(5):789-98.

49. Sirola J, Kroger H. Similarities in acquired factors related to postmenopausal osteoporosis and sarcopenia. J Osteoporos. 2011;2011:536735.

50. Dengel DR, Hagberg JM, Coon PJ, Drinkwater DT, Goldberg AP. Effects of weight loss by diet alone or combined with aerobic exercise on body composition in older obese men. Metabolism. 1994;43(7):867-71.

51. Knoke JD, Barrett-Connor E. Weight loss: a determinant of hip bone loss in older men and women. The Rancho Bernardo Study. Am J Epidemiol. 2003;158(12):1132-8.

52. Hunter GR, Byrne NM, Sirikul B, Fernandez JR, Zuckerman PA, Darnell BE, Gower BA. Resistance training conserves fat-free mass and resting energy expenditure following weight loss. Obesity (Silver Spring). 2008;16(5):1045-51.

53. Lin PH, Ginty F, Appel LJ, Aickin M, Bohannon A, Garnero P, Barclay D, Svetkey LP. The DASH diet and sodium reduction improve markers of bone turnover and calcium metabolism in adults. J Nutr. 2003;133(10):3130-6.

54. Despres JP. Health consequences of visceral obesity. Ann Med. 2001;33(8):534-41.

55. Despres JP. Cardiovascular disease under the influence of excess visceral fat. Crit Pathw Cardiol. 2007;6(2):51-9.

56. Bales $\mathrm{CW}$, Buhr $\mathrm{G}$. Is obesity bad for older persons? A systematic review of the pros and cons of weight reduction in later life. J Am Med Dir Assoc. 2008;9(5):302-12.

57. Bonaiuti D, Shea B, Iovine R, Negrini S, Robinson V, Kemper HC, Wells G, Tugwell P, Cranney A. Exercise for preventing and treating osteoporosis in postmenopausal women. Cochrane Database Syst Rev. 2002(3):CD000333.

58. Hinton PS, Rector RS, Linden MA, Warner SO, Dellsperger KC, Chockalingam A, Whaley-Connell AT, Liu Y, Thomas TR. Weight-loss-associated changes in bone mineral density and bone turnover after partial weight regain with or without aerobic exercise in obese women. Eur J Clin Nutr. 2012;66:606-12. 
59. Villareal DT, Shah K, Banks MR, Sinacore DR, Klein S. Effect of weight loss and exercise therapy on bone metabolism and mass in obese older adults: a one-year randomized controlled trial. J Clin Endocrinol Metab. 2008;93(6):2181-7.

60. Rector RS, Loethen J, Ruebel M, Thomas TR, Hinton PS. Serum markers of bone turnover are increased by modest weight loss with or without weight-bearing exercise in overweight premenopausal women. Appl Physiol Nutr Metab. 2009;34(5):933-41.

61. Bennell KL, Khan KM, Warmington S, Forwood MR, Coleman $\mathrm{BD}$, Bennett MB, Wark JD. Age does not influence the bone response to treadmill exercise in female rats. Med Sci Sports Exerc. 2002;34(12):1958-65.

62. Bray GA. Medical consequences of obesity. J Clin Endocrinol Metab. 2004;89(6):2583-9.

63. Lindstrom J, Peltonen M, Eriksson JG, Aunola S, Hamalainen H, IlanneParikka P, Keinanen-Kiukaanniemi S, Uusitupa M, Tuomilehto J. Determinants for the effectiveness of lifestyle intervention in the Finnish Diabetes Prevention Study. Diabetes Care. 2008;31(5):857-62.

64. Lloyd-Jones D, Adams R, Carnethon M, De Simone G, Ferguson TB, Flegal K, Ford E, Furie K, Go A, Greenlund K, Haase N, Hailpern S, Ho M, Howard V, Kissela B, Kittner S, Lackland D, Lisabeth L, Marelli A, McDermott M, Meigs J, Mozaffarian D, Nichol G, O'Donnell C, Roger V, Rosamond W, Sacco R, Sorlie P, Stafford R, Steinberger J, Thom T, Wasserthiel-Smoller S, Wong N, Wylie-Rosett J, Hong Y. Heart disease and stroke statistics-2009 update: a report from the American Heart Association Statistics Committee and Stroke Statistics Subcommittee. Circulation. 2009;119(3):e21-e181.

65. Tjepkema M, Shields M. Statistics Canada. Adult obesity in Canada: Measured height and weight 2005. http://www.statcan.gc.ca/ pub/82-620-m/2005001/article/adults-adultes/8060-eng.htm. Accessed March 222012.

66. Andersen LB. Physical activity and physical fitness as protection against premature disease or death. Scand J Med Sci Sports. 1995;5(6):318-28.

67. Beevers G, Lip GY, O'Brien E. ABC of hypertension: blood pressure measurement. Part II-conventional sphygmomanometry: technique of auscultatory blood pressure measurement. BMJ. 2001;322(7293):1043-7.

68. Kuo HK, Jones RN, Milberg WP, Tennstedt S, Talbot L, Morris JN, Lipsitz LA. Effect of blood pressure and diabetes mellitus on cognitive and physical functions in older adults: a longitudinal analysis of the advanced cognitive training for independent and vital elderly cohort. J Am Geriatr Soc. 2005;53(7):1154-61.

69. Reisin E, Abel R, Modan M, Silverberg DS, Eliahou HE, Modan B. Effect of weight loss without salt restriction on the reduction of blood pressure in overweight hypertensive patients. N Engl J Med. 1978;298(1):1-6.

70. Vollmer WM, Sacks FM, Ard J, Appel LJ, Bray GA, SimonsMorton DG, Conlin PR, Svetkey LP, Erlinger TP, Moore TJ, Karanja N. Effects of diet and sodium intake on blood pressure: subgroup analysis of the DASH-sodium trial. Ann Intern Med. 2001;135(12):1019-28.

71. Wilsgaard T, Schirmer H, Arnesen E. Impact of body weight on blood pressure with a focus on sex differences: the Tromso Study, 1986-1995. Arch Intern Med. 2000;160(18):2847-53.

72. Neter JE, Stam BE, Kok FJ, Grobbee DE, Geleijnse JM. Influence of weight reduction on blood pressure: a meta-analysis of randomized controlled trials. Hypertension. 2003;42(5):878-84.

73. Statistics Canada. High blood pressure, by age group and sex 2011. http://www40.statcan.ca/101/cst01/health03b-eng.htm. Accessed May 23, 2012.

74. Nicklas BJ, Katzel LI, Bunyard LB, Dennis KE, Goldberg AP. Effects of an American Heart Association diet and weight loss on lipoprotein lipids in obese, postmenopausal women. Am J Clin Nutr. 1997;66(4):853-9.

75. Aucott L, Gray D, Rothnie H, Thapa M, Waweru C. Effects of lifestyle interventions and long-term weight loss on lipid outcomes - a systematic review. Obes Rev. 2011;12(5):e412-25.

76. Short KR, Vittone JL, Bigelow ML, Proctor DN, Rizza RA, Coenen-Schimke JM, Nair KS. Impact of aerobic exercise training on age-related changes in insulin sensitivity and muscle oxidative capacity. Diabetes. 2003;52(8):1888-96. 